\title{
Microworlds for experimental research: Having your (control and collection) cake, and realism too
}

\author{
NICHOLAS DIFONZO \\ Rochester Institute of Technology, Rochester, New York \\ DONALD A. HANTULA \\ Temple University, Philadelphia, Pennsylvania \\ and \\ PRASHANT BORDIA \\ University of Queensland, St. Lucia, Queensland, Australia.
}

\begin{abstract}
Microworlds (MWs) are dynamic computer-generated environments that subjects interact with in the laboratory and that simulate conditions encountered in the field. Precise levels of experimental control and improved accuracy and efficiency of data collection procedures are characteristic of MWs. It is proposed that these benefits are achieved with concomitant gains in internal validity (afforded by high levels of experimental realism) and external validity (afforded by the replication of the temporalinteractive nature of most field phenomena). To illustrate these ideas, three sets of MW studies are described that investigated rumor and behavior in the stock market (BROKER), escalation behavior (INVE\$TMENT CHOICE\$), and the application of foraging theory to internet shopping (CYBERSHOPPER).
\end{abstract}

Two recurrent dilemmas in psychological research are the tensions between realism and control, and between realism and efficiency. One dilemma concerns tradeoffs between realism and experimental control that are often inherent in the choice of research setting (Berkowitz \& Donnerstein, 1982; Dipboye \& Flanagan, 1979; Locke, 1986; Omodei \& Wearing, 1995; Runkel \& McGrath, 1972; Stone, 1977). Laboratory research typically boasts a higher level of experimental control but possesses some degree of artificiality (Asher, 1994). Field research is more realistic but the lack of control often encountered in field settings frequently limits definitive conclusions. Researchers who opt for control through laboratory experimentation may then seek to boost the realism of the laboratory experience, but face yet another tradeoff, this time between realism and data-collection efficiency. Simple

\footnotetext{
We thank Ralph L. Rosnow and three anonymous reviewers for their helpful comments in reviewing earlier drafts of this manuscript. A brief version of this manuscript was presented as part of a symposium, Simulation and Virtual Reality, at the 27th annual conference for the Society for Computers in Psychology, Philadelphia, November 20, 1997. Copies of all programs described here are available by sending the first author three 3.5-in., IBM-formatted, high-density diskettes and a selfaddressed diskette mailer. Correspondence should be addressed to N. DiFonzo, Department of Psychology, Rochester Institute of Technology, 18 Lomb Memorial Dr., Rochester, NY 14623 (e-mail: nxdgss@rit.edu).
}

experiments are likely to yield a large quantity of data for little resources, but data quality may be limited (in part by the unrealistic nature of the experimental task). Elaborate experimental manipulations (e.g., Milgram, 1963) may produce high-quality data (in part because of efforts to improve the realism of the experimental experience), but require a greater amount of time, money, and personnel resources relative to data yield.

Microworlds (MWs) offer a compromise to each of these dilemmas (Brehmer \& Dörner, 1993; Funke, 1991). Among psychological researchers, microworlds refer to dynamic computer-generated environments that subjects interact with in the lab and that simulate conditions encountered in the field (Brehmer \& Dörner, 1993; Funke, 1991; Omodei \& Wearing, 1995). As regards the first dilemma, MWs hold promise in reducing concerns over realism in highly controlled lab studies (Brehmer, 1992; Omodei \& Wearing, 1995). In particular, because of their ability to simulate the complex and dynamic character of field situations, MWs offer superior levels of experimental realism (i.e., subject involvement) and mundane realism (correspondence with the field experience). Regarding the second dilemma, MWs are a moderately efficient means of gathering high-quality data.

These features, combined with the proliferation of inexpensive yet powerful microcomputers, advances in the user friendliness of programming software, and com- 
pelling multimedia capabilities, have led to the emergence of MW research as a viable methodological paradigm in many areas of psychological research (e.g., Andreassen, 1987; Brehmer, 1992; Cohen \& Cyert, 1965; DiFonzo \& Bordia, 1997; Gianutsos, 1994; Hantula \& Crowell, 1994a, 1994b; Lowman \& Norkus, 1987; Omodei \& Wearing, 1995; Rajala \& Hantula, 1997). Some research situations, however, seem especially suited to $\mathrm{MW}$ investigations. Given the above considerations and the benefits described in this manuscript, MW methodologies seem optimal for research (1) involving complex and dynamic phenomena (Brehmer \& Dörner, 1993; Brehmer, Leplat, \& Rasmussen, 1991; Omodei \& Wearing, 1995); (2) in which ethical, practical, or logistical considerations constrain field experimentation or observation (e.g., Ekker, Gifford, Leik, \& Leik, 1988); (3) for which limited resources are available to sustain field investigations (e.g., Schiff, Arnone, \& Cross, 1994); and (4) where it is possible to elicit subject interaction with a microcomputer.

The term microworld possesses a variety of meanings, including representational learning systems (Nesher, 1989), intersecting social systems within which students exist (Goldman, 1996), and programming applications software for use by children so as to enable an interactive, applications-oriented type of learning (Papert, 1980, 1996; Reiber, 1992; Turkle, 1984). More generally, the term has been associated with computer-simulated environments often used for educational or training purposes (Albers, Brand, \& Cellerier, 1991; Good, 1987; Keys, Fulmer, \& Stumpf, 1996). In psychological literature (e.g., Colle \& Green, 1996; Funke, 1991; Perkey, 1986), and especially in the field of decision making, the term has been more rigorously defined. Berndt Brehmer (1992) and Dietrich Dörner (Brehmer \& Dörner, 1993) have most clearly delineated the concept to mean computergenerated simulation environments that real subjects interact with and that possess, to varying degrees, a dynamic (see below), complex (i.e., necessitating multiple considerations by the subject), and opaque (i.e., necessitating exploration) character. MWs simulate an environment, and not the behavioral phenomenon that occurs within that environment, and are therefore distinct from computer simulations that seeks to discover accurate mathematical models of behavior (see, e.g., Rabinowitz \& Feldman, 1989). Moreover, MWs typically simulate interactive environments within which the subject must act repeatedly over time; thus they are not merely the computerized administration of instruments or manipulations. Omodei and Wearing have identified three general applications of MWs: "computerized training simulators (e.g., flight simulators, management training games, etc.), recreational video games (e.g., fantasy adventure games, arcade games, etc.), and simulations specifically developed for theoretically based research into complex decision-making processes" (1995, p. 304). The last application is, of course, our focus here.

\section{EXAMPLES OF MWS FOR EXPERIMENTAL RESEARCH}

This paper describes three sets of MWs created to investigate a diverse set of psychological processes and theories: how rumors affect behavior (BROKER), the behavioral contingencies involved in escalation behavior (INVE\$TMENT CHOICE\$), and the application of foraging theory to economic choice (CYBERSHOPPER). We will use these simulations to illustrate several benefits of MWs in general and to explore methodological assets accruing from realism in particular.

\section{BROKER}

The BROKER MW consisted of an investment game in which subjects could trade one stock for a series of 60 consecutive simulated days (DiFonzo \& Bordia, 1997). On the basis of prediction theory (Ajzen, 1977; Tversky \& Kahneman, 1980), the study manipulated the presence and credibility of information presented concurrent with trading and measured subjects' trading strategies. In an early study, subjects were presented with news, published rumors, unpublished rumors, or no messages, while trading. The game was programmed using the Microsoft QuickBASIC 4.5 programming language and was run on $\mathrm{XT}$ and AT class IBM-PC microcomputers.

At the outset, each subject was assigned $\$ 245$ in cash and $\$ 245$ in the form of seven shares of one stock (Goodyear) valued at $\$ 35$ per share. Subjects dealt with only Goodyear stock and could perform only one transaction during each trading day: They could purchase as many shares as their cash holdings allowed, sell up to the number of shares they currently possessed, or do neither.

\section{INVESTMENT CHOICE\$}

The Investment Choices MW (Hantula \& Crowell, 1994a, 1994b) was used to investigate how changes in the patterning of investment return rates affected investment decisions during trials in which subjects made money or steadily lost money (this research replicated and extended work by Goltz, 1992, who used a similar MW task). The continued investment of resources despite steady losses has been dubbed "escalation and persistence of commitment" in the organizational psychology literature (Hantula, 1992; Staw \& Ross, 1989). At the start of the investment trials, subjects were given a sum of $\$ 10,000$ to manage for an investment firm with explicit instructions to make as much money as they could by investing in stock. At each investment opportunity subjects entered the amount they wanted to invest (with the remainder of the money reserved in a bank account) and were then provided feedback with the amount of gain/loss from their investment. The invest/return feedback cycle continued for a number of investments depending on the particular experiment. INVE\$TMENT CHOICE\$ was programmed in Turbo BASIC (and later updated in QuickBASIC) and run 
on XT- and AT-class IBM-PC computers using a monochrome or color monitor.

The INVE\$TMENT CHOICE\$ display was deliberately sparse and uncluttered. The screen was outlined with a thin line, and in the center of the outlined screen a message told subjects how much money they had available to invest at that time and instructed them to enter their investment in $\$ 100$ increments by pressing the ENTER key. The screen then went blank for a 1-2 sec interval. A message, again centered, then reported the amount of gain or loss on that investment. At the bottom of the screen a reverse-video ribbon appeared that instructed the subject to press any key when finished. This display was used in Hantula and Crowell (1994a). In Hantula and Crowell (1994b), the task and display were changed slightly to that of managing funds in two different markets. One market was denoted by a normal display and the other was denoted by a reverse-video display, but all other features remained the same.

\section{Cybershopper}

The CYBERSHOPPER MW was developed to understand how consumers respond to elements of the on-line shopping experience (Rajala, 1996; Rajala \& Hantula, 1997). The simulation was designed to resemble current America Online shopping websites. Using a mouse to direct their actions and select options, subjects entered and exited stores, checked price and availability, and ordered compact disks (CDs) over 10 sessions. CYBERSHOPPER was programmed in VisualBASIC and run on 486-class PCs equipped with mouse and color monitor.

Subjects would "log on" to the "mall" display, which consisted of logos for five cyberstores arranged in a pentagon on the screen with a neutral-color backing. Clicking on the store logo would allow the subject to "enter the store." Upon entry, the store logos disappeared and a pop-up window with the store name appeared that asked the subject to enter the CD he/she would like to purchase. After a CD was entered, other windows would appear as necessary that advised in-stock status and price and asked for an order.

In the remainder of this manuscript we use these simulations to illustrate three benefits of MWs: enhancements to realism afforded by the simulation of dynamic decision systems, the capacity for precise experimental control, and improvements in data-collection procedures.

\section{DYNAMIC DECISION SYSTEM MODELING}

First, MWs typically present dynamic decision tasks to subjects. Brehmer (1992; cf. Vallacher \& Nowak, 1994) has described a dynamic decision-making task as one in which (1) a series of decisions is required to achieve the goal, (2) the decisions are not independent of one another (i.e., decision parameters change as a result of previous decisions), (3) the decision problem also changes as a result of autonomous system factors, and (4) decisions must be made within a real or simulated time frame. BROKER and INVESTMENT CHOICES illustrate each component of a dynamic decision system in which the decision task was to maximize profit: In BROKER, (1) subjects traded sequentially in a series of 60 trading "days," (2) each decision impacted the parameters of subsequent decisions (e.g., buying stock today may increase/reduce assets available tomorrow), (3) the decision problem changed in response to trading decisions and an autonomous factor (e.g., price changes), and (4) decisions were made in simulated real time (i.e., the computer did not wait beyond $20 \mathrm{sec}$ for a trading decision). In INVESTMENT CHOICE\$, 32 sequential decisions (concerning how much money to invest) were made, the parameters (e.g., current assets available) of which changed over time as a result of autonomous factors (e.g., return rates specified by the experimenter) as well as "investor" actions (e.g., amounts previously invested). In CYBERSHOPPER, subjects attempted to maximize purchasing efficiency over a series of search and purchase decisions the parameters (e.g., price and in-stock availability) of which changed as a result of autonomous factors (e.g., experimenter specifications) and "consumer" actions (e.g., search patterns).

The simulation of dynamic systems is important because most decision phenomena (e.g., stock market trading, resource allocation, shopping on the Internet) are interactive (Vallacher \& Nowak, 1994) and time oriented (Hogarth, 1980) in nature. Unfortunately, results of static (e.g., "paper-and-pencil") methodologies are almost always used to make inferences about dynamic, interactive, and time-oriented phenomena (Elsmore, 1994; Vallacher \& Nowak, 1994). This is a serious drawback of much current psychological research for which the MW paradigm holds great ameliorative potential (DiFonzo, Hantula, \& Bordia, 1997). The implication of this consideration is that the modeling of dynamic decision systems inherent in MW research enhances internal and external validity. We propose that these enhancements are mediated through gains in experimental and mundane realism.

Realism has more than one meaning (Aronson \& Carlsmith, 1968). Experimental realism is the extent to which the experiment is realistic to subjects - that is, the degree to which it involves and affects them, and the degree to which they take it seriously. Mundane realism is the extent to which the experiment is realistic to the situation - that is, the likelihood that experiences encountered in the study will occur in the field. Asch's (1951) classic studies in conformity and Milgram's (1963) memorable investigation of obedience are two examples where subjects were highly involved in the experimental task (as evidenced by physiological reactions), but the experimental events per se of judging the relative lengths of vertical lines and administering increasing doses of electrical voltage rarely occur outside the laboratory. Conversely, in a study by Walster and her associates (Walster, Aronson, \& Abrahams, 1966), subjects read a newspaper article in which a statement of attribution was varied; mun- 
dane realism was very high (because subjects often read newspapers) but experimental realism was quite low (reading a newspaper article was not very involving).

\section{EXPERIMENTAL REALISM}

Because of the ability to simulate dynamic decision systems, we propose that even noncomplex MWs offer a level of experimental realism not often experienced in laboratory research (see, e.g., Omodei \& Wearing, 1995). In our simulations, evidence indicated that experimental realism was high. During BROKER posttrading interviews, subjects reported a high degree of involvement in the task. In addition, a small (but memorable) minority of subjects seemed to be caught up in the task of making money and occasionally pounded their fists on the computer desk and cried with delight (or in agony) as changing stock prices altered the value of their holdings. Similarly, at least 1 subject in INVESTMENT CHOICES became so involved that he hit the return key repeatedly and overloaded the input buffer, thereby "freezing" the program (Hantula, 1989). Many subjects also requested that their earnings be posted outside the lab, as is often done on arcade game machines, and spontaneously recruited their friends to participate. CYBERSHOPPER subjects often remarked about particular stores, and most insisted on taking their shopping lists home with them (Rajala, 1996). Other MW studies have typically reported similar indications of interest (Colle \& Green, 1996; Ekker et al., 1988; Elsmore, 1994; Lowman \& Norkus, 1987).

We speculate that MWs are likely to engender high levels of experimental realism for at least three classes of reasons, most of which flow from the dynamic nature of MW simulations. First, MWs involve the physical and temporal senses. MW multimedia (i.e., sound and video) help to establish a more engrossing experience. Furthermore, MWs evoke a sense of time. People experience the passing of "days," delays, deadlines, and/or temporally related change, all of which may produce a sense of temporality or even urgency. Second, $M W$ s require subjects to be active participants. In this vein, MWs evoke a "hereand-now" type of experience. As with Gestalt psychodrama (see Corey, 1991), MWs represent an action approach: People experience events in the present rather than talking about them in a detached manner. ${ }^{1}$ Similarly, MWs are interactive; that is, the environment changes (partly) as a result of subjects' behavior. Interactivity evokes interest by creating a sense of impact or control in the subject when the environment changes in response to input (Lepper, 1985); witness the ubiquitous popularity of video and computer games. Contrast this with the pallid and inert quality of experiences produced by nondynamic methods in which, for example, subjects read a scenario and role-play one decision, or subjects are asked to imagine that a series of described events occurs. Furthermore, MWs deliver goal-oriented feedback and consequences (often immediately). The involving effects of feedback and consequences are well known (Skinner,
1953, 1969). Payoffs and losses result from subject actions; therefore what a subject does matters.

Third, $M W$ s present challenging tasks in the following ways. They provide opportunity for competition, which appeals to some subjects. Also, MW tasks often mirror real-world goals that subjects view as significant. These have included stopping forest fires (Omodei \& Wearing, 1995), earning profits on investments (e.g., BROKER \& INVESTMENT CHOICE\$), and managing retail operations (Cohen \& Cyert, 1965). In addition, MWs may involve complex problems that demand effortful processing and/ or careful strategical thinking. The preceding reasons are often absent, in part or in whole, from such frequently used psychological methods as survey questionnaires and interviews. It is not surprising that many subjects (often undergraduate students) view participation as boring. Spontaneous comparisons with other studies by BROKER subjects, for example, underscored this idea; subjects found the MW more involving than "the typical psychology experiment." The atypical indications of intense subject interest cited earlier (e.g., requests that INVE\$TMENT CHOICE\$ results be posted, unsolicited recruitment of additional subjects, retention of CYBERSHOPPER shopping lists) also support this idea.

Experimental realism is important because it increases internal validity (Aronson \& Carlsmith, 1968). An experimental result is internally valid when it is due to the manipulation of the independent variable as opposed to artifacts such as demand characteristics. In order to infer that effects are due to the experimental manipulation, subjects should be highly involved and engaged in effortful processing. Otherwise, outcome behaviors may be due to motivational factors (e.g., boredom). The high levels of experimental realism encountered in our MW investigations, for example, bolstered our confidence in the internal validity of these studies. Indeed, one criterion for evaluating MW (internal) validity is the extent of subject involvement. As in our studies, MW experimental realism may be easily measured by self-report of involvement or by direct observation (e.g., nonverbal signs of attentiveness).

\section{MUNDANE REALISM}

When concerned about realism in experiments, however, one typically has mundane realism in mind. Study $A$ is said to be unrealistic to the extent that subjects' phenomenology of the experiment differs from real-life Situation $\mathrm{A}$. The concern over mundane realism stems from a perceived threat to the external validity (i.e., generalizability) of study results. If the experimental manipulation does not sufficiently mimic field experience, one cannot infer that study results apply to field phenomena (see discussion in Schiff et al., 1994). Before addressing this issue with respect to MWs, we note two situations in which generalizability is not of concern.

One situation is where generalizability (and any mundane realism on which it is based) may not be the main 
intent of the study (Berkowitz \& Donnerstein, 1982; Kruglanski, 1975; Mook, 1983). Mook (1983; see also Locke, 1986) has argued that the aim of the study may be to test a theoretical idea using a given setting and with a given sample. It is not the setting or the sample that needs generalizing but the theoretical idea. The BROKER and INVE\$TMENT CHOICE\$ studies, for example, were primarily concerned with testing the theory behind investor actions by predicting how subjects would act in the laboratory. As predicted, changes in source credibility (i.e., news, published rumors, unpublished rumors) failed to cause changes in tracking behavior (in BROKER), whereas changes in reinforcement history had a significant impact on later investing (in INVESTMENT CHOICE\$); therefore, the conceptual basis for these predictions was bolstered. Another example is Brehmer's (1992) firefighting simulation, in which subjects encountered complex and dynamic forest fire scenarios and were charged with managing resources so as to put out the fire. Brehmer omitted many aspects related to firefighting; his studies were not necessarily - nor were they intended to be-externally valid. Rather, they were designed to study "the more general problem of how subjects cope with spatio-temporal processes of the kind exemplified by the fire fighting task" (pp. 214-215). Put another way, the intention of much MW-based research is to map the functional relations between the variables studied in the MW, and not necessarily the surface similarities between the MW and a particular field setting. In this vein, a word of caution is in order: Labeling an MW task (e.g., as a "broker" or "firefighter" activity) may lead some to attribute greater generalizability to the MW than is intended or warranted.

A second situation where generalizability is not of concern involves computer-mediated activities; for these activities, computer-generated simulations are already predisposed toward high levels of mundane realism. In fact, MWs may have increasing mundane realism because so many activities now involve computer interaction. For example, the mundane realism of BROKER and INVESTMENT CHOICES may be supported by the fact that many people invest and manage their funds on-line already. Also, CYBERSHOPPER mundane realism is supported by the increasing popularity of shopping on the net.

For situations in which mundane realism is of concern, however, the matter of how much mundane realism is enough to generalize validly hinges upon a judgment about what features are essential and whether these features are replicated in the simulation (Gianutsos, 1994). For example, in designing BROKER, a conscious attempt was made to define and include such key characteristics of the trading experience as sequential decision making, agreement of rumor with the day's price change, changing prices, and the use of unambiguous news and rumor items. Unlike real trading episodes, though, rumor recipients were unable to discuss the rumor with colleagues, unable to evaluate its likelihood of being veridical on the basis of numerous criteria, were trading novices, did not pay transaction fees, did not use real money, and were exposed to high-variance nonautocorrelated price stimuli in the space of 20 real-time minutes. On the face of it, these drawbacks seem to present a serious challenge to the external validity of findings.

But because MWs have met with success in reproducing key dynamic system features of the field experience (Brehmer, 1992; Cohen \& Cyert, 1965; Gianutos, 1994; Omodei \& Wearing, 1995), we propose that they are more likely to possess higher levels of mundane realism than typical (nondynamic) types of laboratory research. That is, dynamic features may be more integral to the field experience than nondynamic features. BROKER subjects, for example, experienced the "heart" of speculative investing in that they bought and sold assets whose value changed over time, and they were compelled to make predictions within an uncertain environment. Contrast this with how the same phenomenon might be studied without an MWfor example, by asking subjects how rumor/ news would affect the amount of money they would invest or by presenting subjects with a one-time investment decision task. The essential dynamic flavor of speculative investing is sorely missing in the latter examples.

Static methods (i.e., one-time and noninteractive; see, e.g., Lundberg, 1976; Stone, 1977; Thomas \& Tymon, 1982) seem appropriate for stable phenomena, but unfortunately, results of such studies are often generalized to dynamic situations. This is like trying to experience a chord by hearing one note, or trying to understand a symphony by hearing one chord. The problem is one of mixing levels of analyses. A single (static) decision is an independent event; multiple (dynamic) decisions are not independent (Bateman, 1986; Hogarth, 1980; O'Flaherty \& Komaki, 1992; Rachlin, 1990; Rachlin \& Siegel, 1994), thus occupying a separate, horizontal level of analysis. Generalizing from one level to the other may not be warranted. Single decisions may be the product of an entirely different class of variables than are repeated decisions (Sitkin \& Pablo, 1992). It is entirely probable that distinct levels of horizontal analysis may exist (such as a single decision, two decisions in sequence, three in sequence, and greater than three in sequence), and with them issues of pattern and cyclicity (Goltz, 1992; Hantula \& Crowell, 1994b), chaos (Barton, 1994), "strings" of gains and losses (Rachlin, 1990; Rachlin \& Siegel, 1994), and temporal discounting (Ainslie, 1992; Kirby \& Marakovic, 1995), which ought to be considered in a useful understanding of phenomena.

The ability to model dynamic decision systems implies that experiments performed with MWs can be viewed in cybernetic rather than linear terms (Brehmer, 1992). In MWs, the conception of an independent variable moves beyond the manipulation of a single static feature of the experiment (as is often the case when subjects are assigned to different treatment groups). Instead, system characteristics themselves can be used as the independent variables, such as system complexity and feedback delays (e.g., as in CYBERSHOPPER). In the INVESTMENT CHOICES MW, the independent variable was not a single 
event (e.g., the investment return on a single trial), but rather was the temporally extended pattern of gains and losses over the course of the experiment. Dependent variables in MW studies are subject tactics or strategies. In BROKER, trading strategies were indicated by how closely subjects adhered to a buy-low-sell-high behavior pattern (in contrast to, e.g., a single trading decision). This trading pattern is an axiomatic rule for profit making on Wall Street. Such cybernetic approaches are clearly a more mundane-realistic paradigm.

Indeed, generalizability, for all but the most narrow investigative foci, may actually be hindered by excessive attention to mundane realism. This point becomes obvious when one considers the limited generalizability that one achieves even in field studies, which are typically conducted in a single field setting. External validity of field research in psychology has been beset with limitations due to lack of variability in sample selection and measurement strategies (Aronson \& Carlsmith, 1968; Dipboye \& Flanagan, 1979). The use of a manufacturing plant setting, for example, will render the generalizability of study results defunct for a service industry environment. Similarly, the highly detailed simulation of a manufacturing plant setting will render generalizability defunct for a service industry environment. These limitations stem from the fact that, for most research questions, there is no "idealized" or "typical" real-life situation that can be recreated.

Ironically, this fact can make lab simulations that replicate common dynamic features of the field highly generalizable. BROKER and INVESTMENT CHOICE\$ MWs, for example, captured the dynamic character of market investing. CYBERSHOPPER replicated the dynamic character of Internet shopping. A similar argument has been made with regard to "synthetic work tasks" that reproduce "functional aspects of a situation" (Elsmore, 1994, p. 421). Empirical evidence supporting the generalizability of MW studies that represent central features of the realworld experience hales from studies in which behavior in both MW and real-world environments was observed (Ekker et al., 1988; Gianutsos, 1994). For example, subject relocation decision patterns were similar in an MW simulation of the Mt. Saint Helens volcano eruption and actual relocation decisions in 1980 (Ekker et al., 1988). Commenting on generalizability, these researchers concluded: "Thus, to the extent that game-simulation experiments tap actual subject experiences, they generate realistic or externally valid responses" (p. 90).

With these points in mind, we propose that assessing the mundane realism of an MW procedure is determined by how closely the phenomenological experience of the MW corresponds to the essential features of the field experience. Elsewhere (DiFonzo et al., 1997) we have outlined how assessment of this correspondence involves "a) describing the fundamental features of the field experience, b) describing the phenomenological experience of the $M W$, and $c$ ) comparing $a$ ) and $b$ ). These goals may be achieved by asking pilot-phase subjects, experi- enced in the field phenomena under investigation, to perform functions a), b), and c)" (p. 23). For example, to the extent that stockbrokers and Internet shoppers rate central MW and real-world features similarly, MW mundane realism is supported.

\section{CONTROL}

A second benefit of MWs is that they provide a high level of experimental control and thereby heighten confidence that obtained effects are due solely to the experimental manipulation. By "control," we mean the precise uniformity of levels of nonmanipulated variables and the precise variation of levels of manipulated variables (Boring, 1954). Precise uniformity and variation are achieved via reductions in experimenter bias and reductions in experimenter error.

Experimenter bias refers to the (usually unintentional) influence that the experimenter exerts upon subject behavior. For example, in most escalation study tasks, the experimenter provides the feedback to the subject about his/her investment outcomes. If the experimenter conveys this feedback along with a positive or negative facial expression, experimenter bias can be introduced. Rosenthal and his associates have documented how experimenter bias is a powerful confound in a wide variety of human and animal experimental research domains (see Rosenthal \& Rosnow, 1991, for summary). Attempts to reduce experimenter bias depend upon the avoidance of experimenter-subject interactions, especially those in which the experimenter is aware of the hypothesis (Rosenthal \& Rosnow, 1991). For example, instructions may be delivered in writing or may be delivered by an experimenter who is "blind" to the hypothesis under investigation or the condition of the subject. MWs employ this strategy by supplanting human experimenter-subject interactions with (obviously blind) machine-subject interactions (see, e.g., Lowman \& Norkus, 1987). Facial expressions such as smiles and frowns were avoided in the escalation study feedback conveyed in INVESTMENT CHOICES, as well as all other cues that might bias results. A computer can be programmed to avoid "nodding its head," varying its "tone of voice," or providing other subtle cues; had Clever Hans's trainer been an MW, Hans would have been just another horse. ${ }^{2}$ Similar arguments can be made with regard to MW avoidance of effects stemming from human interaction, such as social facilitation $^{3}$ (Guerin, 1993; Zajonc, 1965) and biosocial, psychosocial, situational, and modeling effects (Rosenthal \& Rosnow, 1991).

Experimental error refers to genuine procedural mistakes that arise from our human tendency toward variation. "To err is human," but to maintain uniformity is machinelike. MWs, by virtue of being machine-generated, present a uniform subject experience free of administrative errors (Lowman \& Norkus, 1987). The procedural advantages of automation have been known for some time (e.g., Skinner, 1956, has eloquently described these ben- 
efits in connection with the operant chamber and associated electromechanical programming used in behavioral research). These advantages are especially important because of the likelihood that human error will increase with a dynamic methodological paradigm. Consider how difficult (in some cases impossible) it would be to flawlessly execute BROKER, INVESTMENT CHOICE\$, or CYBERSHOPPER simulations using a human interface. Each of these simulations required repeated, rapid, and multiple data reception, calculation, and response capabilities.

As a machine, therefore, MWs are capable of presenting a precisely invariant (or for that matter, a randomly varying; see Goltz, in press, and Goltz \& Northey, in press) experience with respect to nonmanipulated variables and introduce precise variation with respect to manipulated variables. The three simulations described (cf. Gifford \& Wells, 1991) exemplify the former capability in that, beyond the initial greeting and screening by the research administrator, system characteristics were invariant within conditions. Recent MW studies (Goltz, in press; Goltz \& Northey, in press) in which the variability of investment return rates were randomly computer generated about a mean value in each condition exemplify the latter capability (i.e., controlled variability of the levels of the manipulated variable). Such techniques have not enjoyed widespread use despite the fact that these capabilities offer experimenters greater flexibility as well as increased mundane realism (e.g., random variation of extraneous variables is often a hallmark of the field experience).

Moreover, in the midst of a precisely controlled experience, MWs allow for individualized feedback to individual subjects while responding in a uniform manner to all subjects. This means that it is possible to vary the aspects of feedback to subjects that are germane to the experiment at hand, while other aspects of feedback to subjects can be held constant. For example, in CYBERSHOPPER, the "in/out of stock" message displayed to subjects stated, "the CD you ordered, $x x x$, is not in stock ...," where $x x x$ was the title of the CD. The same message box appeared for all subjects, on the same part of the screen and at the same time (as programmed in the particular experiment). However, the names of the CDs differed to reflect what each individual subject had ordered. The capacity to present subjects with individualized conditions within a uniform manipulation seems paradoxical and represents an important qualitative advance in control methodologies. This capability derives from the cybernetic approach made possible by modern computing technology.

\section{IMPROVEMENTS IN DATA COLLECTION}

A third benefit to be realized by MWs involves the accuracy and efficiency of data-collection procedures. MW data are recorded, coded, and transferred electronically from start to finish. This is rapid, inexpensive, and greatly reduces the possibility of coding errors (see Ekker et al., 1988; Elsmore, 1994; Gianutsos, 1994; Gifford \& Wells, 1991; Schiff et al., 1994). Confidence in data integrity is thereby enhanced. For example, BROKER measured trading behavior automatically by computing the Fisher $z$ transformation of the Pearson $r$ for the price of the stock and the number of shares held at the end of each trading day. Each subject's total number of shares traded (volume), profit, and profits per share traded were also automatically calculated and recorded. In addition, number of shares held, amount of cash available, number of shares that could be bought, and total assets were all automatically recorded for each of the 60 simulated days. The accurate collection of such a voluminous amount of data necessitated a computer methodology.

Enhancements to efficiency stem from greater experimental control (as discussed above) and from the use of machine labor. If within-condition variance is minimized through the use of good experimental procedures (i.e., higher experimental control), then fewer subjects are needed for any given expected effect size, and independent variables with smaller effects can be investigated (i.e., power is increased). More parametric studies can thereby be executed, resulting in a more systematic treatment of a research question. Each simulation presented in this manuscript was used in a series of studies that methodically altered experimental manipulations. For example, BROKER began with news and no-message conditions, added published rumor, unpublished rumor, and irrelevant news conditions in two subsequent studies, used thought-stopping techniques in a later study, and then varied message-price-change congruence. In addition, interlab replications become more feasible because many idiosyncratic laboratory variations are eliminated. Furthermore, if studies use machine, rather than human, resources, then experiments may be run more quickly, fewer experimenter human resources are needed, and data can be analyzed sooner. Problems and artifacts can thereby be detected earlier and corrected, and studies may be rerun in a timely fashion. Of course, the ethical implications of all these points are positive. With increased efficiency, fewer resources are squandered, fewer subjects' daily routines are disrupted, and a greater research "bang for our buck" is obtained (Rosnow \& Rosenthal, 1997; Rosnow, Rotheram-Borus, Ceci, Blanck, \& Koocher, 1993).

\section{SUMMARY}

The MW paradigm brings certain favorable features to experimental research in psychology, including high levels of control and improvements in data-collection accuracy and efficiency. These achievements are not made at the expense of subject involvement and generalizability, as is usually the case with other methodologies. Indeed, the most noteworthy contribution of MW simulations may be the enhanced internal validity they bring to the research by providing higher experimental realism and by the increased external validity afforded by dynamic kinds of mundane realism. It therefore seems likely that MWs will transform the nature of the split between laboratory and field research from a yawning chasm to a 
mere fracture 4 (Brehmer \& Dörner, 1993). Finally, MWs are an important methodological innovation because they are the machinery necessary for a paradigm shift to dynamical frameworks (Vallacher \& Nowak, 1994). As operant chambers are to behavior analysis, so MWs are to a dynamic psychology.

\section{REFERENCES}

AINSLIE, G. (1992). Picoeconomics: The strategic interaction of successive motivational states within the person. New York: Cambridge University Press.

AJZEN, I. (1977). Intuitive theories of events and the effects of base-rate information on prediction. Journal of Personality \& Social Psychology, 35, 303-314.

Albers, G., Brand, H., \& Cellerier, G. (1991). A microworld for genetic artificial intelligence. In M. Yazdani \& R. W. Lawler (Eds.), Artificial intelligence and education (Vol. 2, pp. 63-77). Norwood, $\mathrm{NJ}$ : Ablex.

ANDREASSEN, P. B. (1987). On the social psychology of the stock market: Aggregate attributional effects and the regressiveness of prediction. Journal of Personality \& Social Psychology, 53, 490-496.

Aronson, E., \& Carlsmith, J. M. (1968). Experimentation in social psychology. In G. Lindzey \& E. Aronson (Eds.), The handbook of social psychology (2nd ed., Vol. 2, pp. 1-79). Reading, MA: AddisonWesley.

AscH, S. (1951). Effects of group pressure upon the modification and distortion of judgment. In H. Guetzkow (Ed.), Groups, leadership, and men (pp. 177-190). Pittsburgh: Carnegie Press.

AsHER, W. (1994). Experimental controls. In R. J. Corsini (Ed.), Encyclopedia of psychology (2nd ed., Vol. 1, p. 521). New York: Wiley.

BARTON, S. (1994). Chaos, self-organization, and psychology. American Psychologist, 49, 5-14.

BATEMAN, T. S. (1986). The escalation of commitment in sequential decision making: Situational and personal moderators and limiting conditions. Decision Sciences, 17, 33-49.

Berkowitz, L., \& Donnerstein, E. (1982). External validity is more than skin deep: Some answers to criticisms of laboratory experiments. American Psychologist, 37, 245-257.

BORING, E. G. (1954). The nature and history of experimental control. American Journal of Psychology, 67, 573-589.

BREHMER, B. (1992). Dynamic decision making: Human control of complex systems. Acta Psychologica, 81, 211-241.

BREHMER, B., \& DörNer, D. (1993). Experiments with computersimulated microworlds: Escaping both the narrow straits of the laboratory and the deep blue sea of the field study. Computers in Human Behavior, 9, 171-184.

BREHMER, B., LePlat, J., \& RASMussen, J. (1991). Use of simulation in the study of complex decision making. In J. Rasmussen, B. Brehmer, \& J. Leplat (Eds.), Distributed decision making: Cognitive models for cooperative work (pp. 373-386). New York: Wiley.

COHEN, K., \& CYERr, R. N. (1965). Simulation of organizational behavior. In James G. March (Ed.), Handbook of organizations (pp. 305334). Chicago: Rand McNally.

COLle, H. A., \& GREEN, R. F. (1996). Introductory psychology laboratories using graphic simulations of virtual subjects. Behavior Research Methods, Instruments, \& Computers, 28, 331-335.

COREY, G. (1991). Theory and practice of counseling and psychotherapy (4th ed.). Pacific Grove, CA: Brooks/Cole.

DiFonzo, N., \& BordiA, P. (1997). Rumor and prediction: Making sense (but losing dollars) in the stock market. Organizational Behavior \& Human Decision Processes, 71, 329-353.

Difonzo, N., Hantula, D. A., \& Bordia, P. (1997). Microworlds for a dynamic I/O psychology in the 21 st century. The IndustrialOrganizational Psychologist, 35, 19-25.

DipbOYE, R. L., \& FlanaGan, M. F. (1979). Research settings in industrial and organizational psychology: Are findings in the field more generalizable than in the laboratory? American Psychologist, 34, 141-150.

EKKER, K., GifFord, G., LeIK, S. A., \& LEIK, R. K. (1988). Using micro- computer game-simulation experiments to study family response to the Mt. St. Helens eruptions. Social Science Computer Review, 6, 90-105.

ELSMORE, T. F. (1994). SYNWORK1: A PC-based tool for assessment of performance in a simulated work environment. Behavior Research Methods, Instruments, \& Computers, 26, 421-426.

FUNKE, J. (1991). Dealing with dynamic systems: Research strategy, diagnostic approach and experimental results. German Journal of Psychology, 16, 24-43.

Gianutsos, R. (1994). Driving advisement with the Elemental Driving Simulator (EDS): When less suffices. Behavior Research Methods, Instruments, \& Computers, 26, 183-186.

GiFFORD, R., \& WELLS, J. (1991). FISH: A commons dilemma simulation. Behavior Research Methods, Instruments, \& Computers, 23, 437-441. Goldman, S. V. (1996). Mediating microworlds: Collaborating on high school science activities. In T. Koschmann (Ed.), CSCL: Theory and practice of an emerging paradigm (pp. 45-83). Mahwah, NJ: Erlbaum.

GoLTZ, S. M. (1992). A sequential learning analysis of decisions in organizations to escalate investments despite continuing costs or losses. Journal of Applied Behavior Analysis, 25, 561-574.

Goltz, S. M. (in press). Can't stop on a dime: The roles of matching and momentum in persistence of commitment. Journal of Organizational Behavior Management.

GolTZ, S. M., \& NORTHEY, J. E., JR. (in press). Simulating the variability of actual outcomes. Behavior Research Methods, Instruments, \& Computers.

GooD, R. (1987). Artificial intelligence and science education. Journal of Research in Science Teaching, 24, 325-342.

GuERIN, B. (1993). Social facilitation. Paris: Cambridge University Press. HANTULA, D. A. (1989). Investment and resource allocation following partial returns: An analysis of persistence, escalation, and contrast effects. Unpublished doctoral dissertation, University of Notre Dame.

HANTULA, D. A. (1992). The basic importance of escalation. Journal of Applied Behavior Analysis, 25, 579-583.

Hantula, D. A., \& Crowell, C. R. (1994a). Behavioral contrast in a two-option analogue task of financial decision making. Journal of Applied Behavior Analysis, 27, 607-617.

Hantula, D. A., \& Crowell, C. R. (1994b). Intermittent reinforcement and escalation processes in sequential decision making: A replication and theoretical analysis. Journal of Organizational Behavior Management, 14, 7-36.

HogarTh, R. M. (1980). Beyond discrete biases: Functional and dysfunctional aspects of judgmental heuristics. Psychological Bulletin, 90, 197-217.

Keys, J. B., Fulmer, R. M., \& StumpF, S. S. (1996). Microworlds and simuworlds: Practice fields for the learning organization. Organizational Dynamics, 24, 36-49.

Kirby, K. N., \& Marakovic, N. N. (1995). Modeling myopic decisions: Evidence for hyperbolic delay-discounting within subjects and amounts. Organizational Behavior \& Human Decision Processes, 64, 22-30.

KRUGLANSKI, A. W. (1975). The human subject in the psychology experiment: Fact and artifact. In L. Berkowitz (Ed.), Advances in experimen tal social psychology (Vol. 8, pp. 101-147). New York: Academic Press.

LEPPER, M. R. (1985). Microcomputers in education: Motivational and social issues. American Psychologist, 40, 1-18.

LOCKE, E. A. (ED.) (1986). Generalizing from laboratory to field settings: Research findings from industrial-organizational psychology, organizational behavior, and human resource management. Lexington, MA: Lexington Books.

Lowman, J., \& NoRkus, M. (1987). The SuperShrink interview: Active versus passive questioning and student satisfaction. Computers in Human Behavior, 3, 181-192.

LuNDBERG, C. C. (1976). Hypothesis creation in organizational behavior research. Academy of Management Review, 1, 5-12.

MILGRam, S. (1963). Behavioral study of obedience. Journal of Abnormal Social Psychology, 67, 371-378.

Mook, D. G. (1983). In defense of external invalidity. American Psychologist, 38, 379-387.

Nesher P. (1989). Microworlds in mathematical education: A pedagogical realism. In L. B. Resnick (Ed.), Knowing, learning, and instruction: Essays in honor of Robert Glaser (pp. 187-215). Hillsdale, $\mathrm{NJ}$ : Erlbaum. 
O'Flaherty, B., \& Komakı, J. L. (1992). Going beyond with Bayesian updating. Journal of Applied Behavior Analysis, 25, 590-612.

OMODEI, M. M., \& Wearing, A. J. (1995). The Fire Chief microworld generating program: An illustration of computer-simulated microworlds as an experimental paradigm for studying complex decisionmaking behavior. Behavior Research Methods, Instruments, \& Computers, 27, 303-316.

PAPERT, S. (1980). Mindstorms: Children, computers, and powerful ideas. New York: Basic Books.

PAPERT, S. (1996). The connected family: Bridging the digital generation gap. Atlanta: Longstreet.

Perkey, M. N. (1986). The effect of a machine-rich environment on courseware development: The process and the product. Behavior Research Methods, Instruments, \& Computers, 18, 196-204.

PODSAKOFF, P. M., \& ORGAN, D. (1986). Self-reports in organizational research: Problems and prospects. Journal of Management, 12, 531-544.

Quintanar, L. R., CrowelL, C. R., \& Moskal, P. J. (1987). The interactive computer as a social stimulus in human-computer interactions. In G. Salvendy, S. L. Sauter, \& J. J. Hurrell, Jr. (Eds.), Social, ergonomic, and stress aspects of work with computers (pp. 303-310). Amsterdam: Elsevier.

Rabinowitz, M., \& Feldman, S. (1989). Using computer simulations to investigate individual differences: A look at an addition retrieval model. Learning \& Individual Differences, 1, 227-246.

RACHLIN, H. R. (1990). Why do people gamble and keep gambling despite heavy losses? Psychological Science, 1, 294-297.

RaCHLIN, H., \& Siegel, E. (1994). Temporal patterning in probabilistic choice. Organizational Behavior \& Human Decision Processes, 59, 161-176.

RAJALA, A. K. (1996). Foraging for a living in the electronic jungle: Extending the matching law and the delay-reduction hypothesis to consumer behavior on the Internet. Unpublished doctoral dissertation, Temple University, Philadelphia.

Rajala, A. K., \& Hantula, D. A. (1997). The behavioral ecology of consumption: Delay reduction in a simulated online shopping mall. Manuscript submitted for publication.

REIBER, L. P. (1992). Computer-based microworlds: A bridge between constructivism and direct instruction. Educational Technology Research \& Development, 40, 93-106.

ROSENTHAL, R., \& RosNow, R. L. (1991). Essentials of behavioral research: Methods and data analysis (2nd ed.). New York: McGraw-Hill.

Rosnow, R. L., \& Rosenthal, R. (1997). People studying people: Artifacts and ethics in behavioral research. New York: Freeman.

Rosnow, R. L., Rotheram-Borus, M. J., Ceci, S. J., Blanck, P. D., \& Koocher, G. P. (1993). The Institutional Review Board as a mirror of scientific and ethical standards. American Psychologist, 48, 821-826.

RUNKEL, P. J., \& MCGRATH, J. E. (1972). Research on human behavior: A systematic guide to method. New York: Holt, Rinehart \& Winston.
Schiff, W., ARnone, W., \& Cross, S. (1994). Driving assessment with computer-video scenarios: More is sometimes better. Behavior Research Methods, Instruments, \& Computers, 26, 192-194.

SitKIN, S. B., \& PABLO, A. L. (1992). Re-conceptualizing the determinants of risk behavior. Academy of Management Review, 17, 9-38.

SkINNER, B. F. (1953). Science and human behavior. New York: Free Press.

SKINNER, B. F. (1956). A case history in scientific method. American Psychologist, 11, 221-233.

SKINNER, B. F. (1969). Contingencies of reinforcement: $A$ theoretical analysis. Englewood Cliffs, NJ: Prentice-Hall.

STAW, B. M., \& Ross, J. (1989). Understanding behavior in escalation situations. Science, 246, 216-220.

STONE, E. (1977). Research in organizational behavior. Glenview, IL: Scott, Foresman.

Thomas, K. W., \& TYmon, W. G. (1982). Necessary properties of relevant research: Lessons from recent criticisms of the organizational sciences. Academy of Management Review, 7, 345-352.

TURKLE, S. (1984). The second self: Computers and the human spirit. New York: Simon \& Schuster.

TVERSKY, A., \& KaHNEMAN, D. (1980). Causal schemas in judgments under uncertainty. In M. Fishbein (Ed.), Progress in social psychol$o g y$ (pp. 49-72). Hillsdale, NJ: Erlbaum.

VALLACHER, R. R., \& NowAK, A. (1994). Dynamical systems in social psychology. San Diego: Academic Press.

Walster, E., ARonson, E., \& Abrahams, D. (1966). On increasing the persuasiveness of a low prestige communicator. Journal of Experimental Social Psychology, 2, 325-342.

ZAJONC, R. B. (1965). Social facilitation. Science, 149, 269-274.

\section{NOTES}

1. With this also come attendant advantages of observational over self-report data (see Podsakoff \& Organ, 1986).

2. The case of Clever Hans has been used to illustrate experimental bias (Rosenthal \& Rosnow, 1991). Hans was a horse who answered simple math, spelling, and history questions correctly by stomping one hoof. Hans's academic accomplishments were in reality achieved via subtle and unintentional visual cues delivered by his trainer.

3. Of course, a computer interface can also take on socially facilitative control of behavior and people will attribute causality to the computer if it has a human-like interface (Quintanar, Crowell, \& Moskal, 1987).

4 . We are indebted to an anonymous reviewer for this excellent metaphor.

(Manuscript received October 23, 1997; revision accepted for publication January 21, 1998.) 